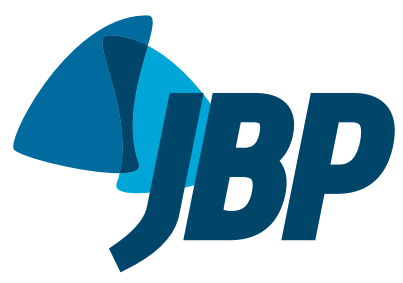

\title{
Longitudinal follow-up of cardiac vagal activity in individuals undergoing endoscopic thoracic sympathectomy
}

\author{
Ana Paula Ferreira ${ }^{1,2,3, a}$, Plinio dos Santos Ramos ${ }^{1,2,3, b}$, Jorge Montessi²,3,4,c, \\ Flávia Duarte Montessi ${ }^{2,3, d}$, Eveline Montessi Nicolini ${ }^{3,4, e}$, \\ Edmilton Pereira de Almeida ${ }^{4, f}$, Djalma Rabelo Ricardo ${ }^{1,2,3,9}$
}

1. Programa de Pós-Graduação Strictu Sensu, Universidade do Estado do Rio de Janeiro - UERJ Rio de Janeiro (RJ) Brasil.

2. Faculdade de Ciências Médicas e da Saúde de Juiz de Fora - FCMS/JF Juiz de Fora (MG) Brasil.

3. Hospital e Maternidade Therezinha de Jesus - HMTJ - Juiz de Fora (MG) Brasil.

4. Hospital Monte Sinai, Juiz de Fora (MG) Brasil.

a. (D) http://orcid.org/0000-0002-5761-798X

b. (D) http://orcid.org/0000-0003-4035-3890

c. (D) http://orcid.org/0000-0002-0143-8384

d. (iD) http://orcid.org/0000-0001-7736-3094

e. (iD) http://orcid.org/0000-0002-4973-2398

f. (D) http://orcid.org/0000-0001-5510-0015

g. (D) http://orcid.org/0000-0003-2456-1470

Submitted: 19 December 2017 Accepted: 10 April 2018.

Study carried out at the Faculdade de Ciências Médicas e da Saúde de Juiz de Fora - FCMS/JF - Juiz de Fora (MG)

\begin{abstract}
Objective: To conduct a longitudinal investigation of cardiac vagal activity (CVA) by measuring resting $\mathrm{HR}$ and calculating the cardiac vagal index (CVI) in individuals undergoing sympathectomy for the treatment of primary hyperhidrosis. Methods: This was a descriptive longitudinal study involving 22 patients, 13 of whom were female. The mean age was $22.5 \pm 8.8$ years. The palms, soles, and axillae were the most commonly affected sites. Resting HR was measured by an electrocardiogram performed 20 min before the 4-second exercise test (4sET), which was used in order to evaluate CVA at three different time points: before surgery, one month after surgery, and four years after surgery. Results: Resting HR (expressed as mean \pm SE) was found to have decreased significantly at 1 month after surgery (73.1 \pm 1.6 bpm before surgery vs. $69.7 \pm 1.2$ bpm at one month after surgery; $p=0.01)$. However, the HR values obtained at four years after surgery tended to be similar to those obtained before surgery $(p=0.31)$. The CVI (expressed as mean \pm SE) was found to have increased significantly at one month after surgery $(1.44 \pm 0.04$ before surgery vs. $1.53 \pm 0.03$ at one month after surgery; $p=$ 0.02). However, the CVI obtained at four years after surgery tended to be similar to that obtained before surgery $(p=0.10)$. Conclusions: At one month after sympathectomy for primary hyperhidrosis, patients present with changes in resting HR and CVA, both of which tend to return to baseline at four years after surgery.
\end{abstract}

Keywords: Hyperhidrosis; Sympathectomy; Autonomic nervous system; Exercise test; Electrocardiography. Brasil.

\section{INTRODUCTION}

Primary or essential hyperhidrosis is a disorder that is characterized by uncontrollable excessive sweating of unknown cause. ${ }^{(1)}$ It primarily affects the axillae, palms, soles, and face, causing intense discomfort and having a negative effect on social, emotional, and professional functioning. ${ }^{(2)}$

The clinical treatment of hyperhidrosis can be topical, electrical, or systemic; however, in most cases, surgery is the only effective treatment option. The increasing availability of video-assisted thoracic surgery plays a decisive role in establishing sympathectomy as the gold standard for definitive treatment of severe hyperhidrosis. ${ }^{(3,4)}$

It is well described in the literature that the sympathetic and parasympathetic nervous systems are involved in autonomic cardiovascular control, ${ }^{(5-7)}$ and that T2, T3, and T4 sympathetic ganglia are responsible for cardiac control. ${ }^{(8)}$ Several studies have investigated the effects of sympathectomy on the autonomic nervous system, having found changes in autonomic cardiac function after surgical intervention. ${ }^{(8-11)}$ However, in the aforementioned studies, assessment of heart rate variability (HRV) was the only method used in order to assess cardiovascular autonomic function. Although HRV assessment is a widely used method, it is poorly reproducible.

Cardiovascular autonomic dysfunction is associated with an increased risk of mortality, which is primarily due to reduced vagal activity. ${ }^{(12-14)}$ Therefore, an investigation of the parasympathetic nervous system in patients with hyperhidrosis appears to be useful from a clinical standpoint, contributing to future therapeutic strategies for heart disease patients. The objective of the present study was to conduct a longitudinal investigation of cardiac vagal activity (CVA) by measuring resting HR and calculating the cardiac vagal index (CVI) in individuals undergoing sympathectomy for the treatment of primary hyperhidrosis.

\section{METHODS}

\section{Sample}

This was a descriptive longitudinal study involving 22 patients, 13 of whom were female. The mean age

Correspondence to:

Djalma Rabelo Ricardo. Faculdade de Ciências Médicas e da Saúde de Juiz de Fora, SUPREMA, Alameda Salvaterra, 200, Salvaterra, CEP 36033-003, Juiz de Fora, MG, Brasil.

Tel.: 5532 98886-2891. E-mail: djalmaricardo@suprema.edu.br

Financial support: None. 
was $22.5 \pm 8.8$ years (range, $12-45$ years). All of the study participants sought surgical treatment (sympathectomy) for hyperhidrosis, and none had a history of cardiovascular disease. All of the study participants had primary hyperhidrosis of varying severity. The palms and soles were the most commonly affected sites, followed by the axillae and face. The exclusion criteria were as follows: being a smoker; being unable to perform the 4-second exercise test (4sET); being obese (i.e., having a body mass index > $30 \mathrm{~kg} / \mathrm{m}^{2}$ ); and using medications potentially affecting the autonomic nervous system. Smokers were defined as those who had smoked one or more cigarettes in the 30 days preceding the study.

The study participants were evaluated at a teaching hospital in the city of Juiz de Fora, Brazil, between January of 2010 and December of 2014, at three different time points: before surgery, 1 month after surgery, and 4 years after surgery. The present study was approved by the local research ethics committee (Ruling no. $1,324,807$ ). All of the study participants gave written informed consent.

Height (in $\mathrm{cm}$ ) was measured to the nearest 0.1 $\mathrm{cm}$ with a stadiometer (Sanny; American Medical do Brasil Ltda., São Bernardo do Campo, Brazil), and body weight (in $\mathrm{kg}$ ) was measured to the nearest $0,1 \mathrm{~kg}$ with a digital scale (Welmy, São Paulo, Brazil). Blood pressure was measured at rest. ${ }^{(15)}$ At the three time points, participants underwent assessment of CVA by analysis of resting HR and the 4sET, which was performed on a cycle ergometer.

\section{Sympathectomy}

Sympathectomy was performed with patients in the supine position, with both arms extended laterally at a $70^{\circ}$ angle to the ipsilateral hemithorax and resting comfortably on a customized armrest. Patients subsequently underwent total intravenous anesthesia and endotracheal intubation, patient weight being taken into account in order to adjust mechanical ventilation settings. Throughout the procedure, patients received ventilatory support at a tidal volume of $7 \mathrm{~mL} / \mathrm{kg}$ of body weight, a respiratory rate of 12 breaths/min, and an $\mathrm{FiO}_{2}$ of $100 \%$. For standardization purposes, all surgical procedures were on the right side, sympathectomy being performed at T4, T5, and T6. Apnea duration was assessed by capnography and expressed as disconnection time, which was used as a proxy for surgical time (i.e., the time elapsed between insertion and removal of the trocar through which a video camera and electrocautery device were inserted). The surgical procedure was discontinued if pulse oximetry showed an $\mathrm{SpO}_{2}$ of $<90 \%$ on room air, patients being ventilated until pulse oximetry showed an $\mathrm{SpO}_{2}>98 \%$ on room air.

\section{Resting HR}

Resting HR was obtained by a continuous recording of a single electrocardiographic lead (CC5 or CM5) with the PowerLab system (PowerLab 4/26T and Lab Chart Pro 7 software; ADInstruments Pty Ltd, Bella Vista, Australia), with an accuracy of $1 \mathrm{~ms}$.

\section{$4 s E T$}

The $4 \mathrm{sET}$ is performed in order to evaluate the parasympathetic nervous system alone over the course of $4 \mathrm{~s}$ of exercise performed during a 12-s breath hold following a maximal inspiratory maneuver. The $4 \mathrm{sET}$ is performed on a cycle ergometer and consists of pedaling as fast as possible without load from the 5 th to the 9 th second of a 12-s breath hold following a maximal inspiratory maneuver. The 4sET quantifies CVA through the CVI, which represents HR acceleration triggered reflexively by cardiac vagal inhibition. Individuals performing the 4sET are required to follow four consecutive commands: first, a maximal inspiratory maneuver performed rapidly through the mouth; second, pedaling as fast as possible; third, an abrupt stop; and fourth, an expiratory maneuver. ${ }^{(16,17)}$

The CVI is a dimensionless index obtained by the 4sET, being the ratio between the RR interval immediately before exercise (or the first RR interval during exercise, whichever is longer) and the shortest RR interval during exercise (which is typically the last RR interval).

The 4sET allows evaluation of the integrity of the parasympathetic nervous system alone and was used in the present study because it would have been impossible to measure CVA accurately and noninvasively by other methods for cardiovascular autonomic function assessment. In addition, the 4 sET is reliable ${ }^{(16)}$ and has been pharmacologically validated. ${ }^{(18)}$ The system that was used for measuring resting HR was also used for electrocardiographic recordings.

\section{Statistical analysis}

The Shapiro-Wilk test was used in order to determine the distribution of the data, which was found to be normal. For all autonomic function variables, the paired Student's t-test and one-way ANOVA were used. The level of significance was set at 5\%. Statistical analysis was performed with the GraphPad software, version 5.01 (GraphPad Inc., San Diego, CA, USA).

\section{RESULTS}

A total of 22 patients, 13 of whom were female, underwent sympathectomy for the treatment of primary hyperhidrosis, their mean age being $22.5 \pm 8.8$ years (range, 12-45 years). Of those 22 patients, only 12 (7 of whom were female) returned for a follow-up evaluation 4 years after surgery, their mean age being $25.6 \pm 8.2$ years. The demographic characteristics of the study sample are shown in Table 1.

Resting HR (expressed as mean $\pm \mathrm{SE}$ ) was measured by an electrocardiogram performed 20 min before the $4 \mathrm{sET}$ and was found to have decreased significantly at 1 month after surgery $(73.1 \pm 1.6 \mathrm{bpm}$ before surgery vs. $69.7 \pm 1.2 \mathrm{bpm}$ at 1 month after surgery; $\mathrm{p}=$ 
0.01). At 4 years after surgery, resting HR was found to be $72.1 \pm 1.7 \mathrm{bpm}(\mathrm{p}=0.31)$, meaning that the HR values obtained at 4 years after surgery tended to be similar to those obtained before surgery. These results are shown in Figure 1.

The CVI (as assessed by the 4sET and expressed as mean $\pm \mathrm{SE}$ ) reflects the magnitude of parasympathetic modulation of $\mathrm{HR}$, a significant difference being found between the CVI obtained before surgery and the CVI obtained at 1 month after surgery $(1.44 \pm 0.04$ vs. $1.53 \pm 0.03 ; p=0.02$ ). As can be seen in Figure 2, the CVI obtained at 4 years after surgery tended to be similar to that obtained before surgery $(p=0.10)$.

\section{DISCUSSION}

Hyperhidrosis severely affects the social life, quality of life, self-confidence, and character of patients. The surgical treatment of primary hyperhidrosis is aimed at improving all of the above by means of ablation of thoracic sympathetic ganglia. ${ }^{(19)}$ However, surgical complications such as compensatory sweating are common and not always preventable. Therefore, in the present study, ablation was performed at T4, T5, and $\mathrm{T} 6$ because compensatory sweating rates are known to be lower when sympathectomy is performed at those levels. ${ }^{(4)}$

The sympathetic fibers that innervate the heart, lungs, and other thoracic viscera can also be affected because they lie along the surgical path. Therefore, autonomic changes (particularly sympathetic nervous system changes) resulting from such surgical procedures are theoretically unavoidable. ${ }^{(20)}$

Although sympathetic cardiac changes are expected to occur after sympathectomy, ${ }^{(21)}$ little is known about the effect of sympathectomy on CVA. In the present study, significant differences were found between the preoperative and postoperative period regarding resting $\mathrm{HR}$ and the CVI, CVA having increased at 1 month after surgery. This finding is consistent with those of Cruz et al.,(22) who analyzed HRV through 24-h Holter monitoring after T2-T3 sympathectomy and found an increase in high-frequency (HF) power in normalized units, a reduction in low-frequency (LF) power in normalized units, and a reduction in the LF/ HF ratio 2 weeks after surgery.

Schmidt et al. ${ }^{(23)}$ longitudinally followed individuals undergoing sympathectomy for hyperhidrosis and compared them with matched controls, calculating HRV and sequential baroreflex sensitivity at three different time points (before surgery, 6 months after surgery, and 12 months after surgery). At 12 months after surgery, significant differences were found between patients and controls regarding HRV, which subsequently returned to relatively normal values. These findings suggest that sympathectomy resulted in reduced sympathetic activity and increased cardiac parasympathetic activity. However, there were no significant changes in sequential baroreflex sensitivity.

Our findings suggest a significant increase in parasympathetic activity at 1 month after surgery. In

Table 1. Demographic characteristics of the study sample. ${ }^{\text {a }}$

\begin{tabular}{lccc} 
Characteristic & $\begin{array}{c}\text { Before surgery } \\
(\mathbf{N}=\mathbf{2 2})\end{array}$ & $\begin{array}{c}\text { One month after surgery } \\
(\mathbf{N}=\mathbf{2 2})\end{array}$ & $\begin{array}{c}\text { Four years after surgery } \\
\text { (n }=12)\end{array}$ \\
\hline Age & $22.5 \pm 8.8$ & $22.5 \pm 8.8$ & $25.6 \pm 8.2$ \\
Weight, $\mathrm{kg}$ & $62.7 \pm 13.2$ & $62.6 \pm 13.3$ & $65.0 \pm 11.5$ \\
Height, m & $1.7 \pm 0.1$ & $1.7 \pm 0.1$ & $1.7 \pm 0.1$ \\
$\mathrm{BMI}, \mathrm{kg} / \mathrm{m}^{2}$ & $22.4 \pm 2.9$ & $22.4 \pm 2.9$ & $22.8 \pm 2.6$ \\
$\mathrm{SBP}, \mathrm{mmHg}$ & $113.5 \pm 12.4$ & $111.8 \pm 10.2$ & $117.0 \pm 9.2$ \\
DBP, $\mathrm{mmHg}$ & $74.6 \pm 9.9$ & $75.4 \pm 9.2$ & $75.5 \pm 8.5$ \\
\hline
\end{tabular}

BMI: body mass index; SBP: systolic blood pressure; and DBP: diastolic blood pressure. aValues expressed as mean \pm SD.

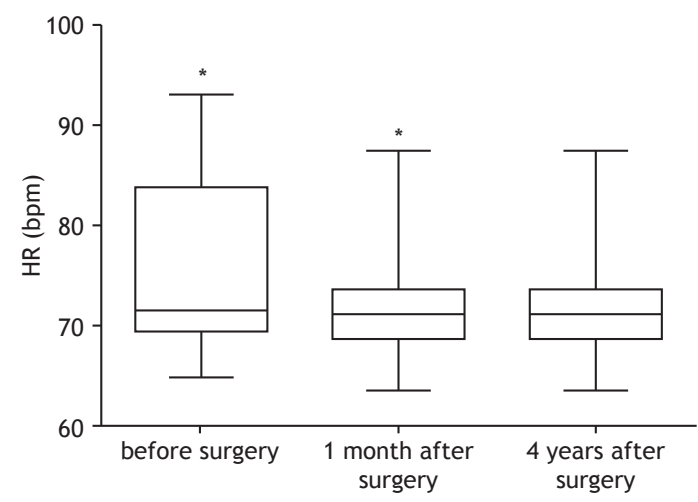

Figure 1. Resting HR before surgery, one month after surgery, and four years after surgery. ${ }^{*} p=0.01$.

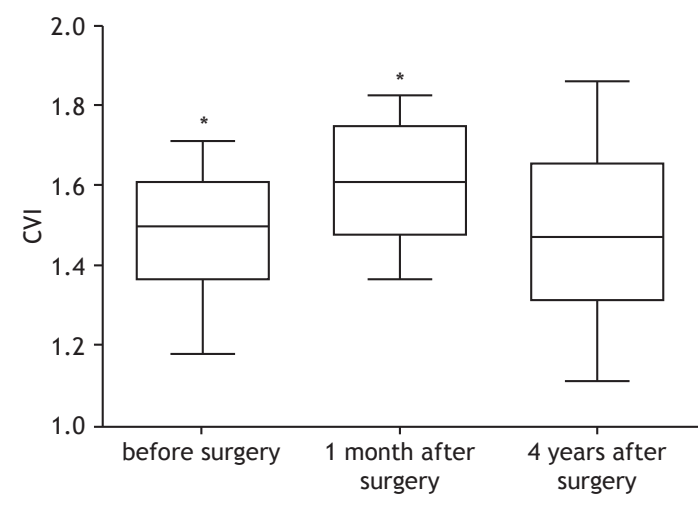

Figure 2. Cardiac vagal index (CVI) before surgery, one month after surgery, and four years after surgery. ${ }^{*} p=0.02$. 
contrast, Wiklund et al.(8) measured HRV and found a reduction in LF power after sympathectomy, with no significant increase in HF power; after 6 months of follow-up, LF power remained at a lower level, whereas HF power decreased, returning to baseline values. The authors concluded that sympathectomy results in an initial sympathovagal imbalance, with a parasympathetic predominance, which is restored in the long term.

Senard et al.(24) investigated 19 patients with hyperhidrosis and 20 age-matched healthy controls and found no significant differences between the two groups regarding LF or HF power in normalized units during HRV assessment, a finding that is consistent with those of another study comparing hyperhidrosis patients and healthy controls. ${ }^{(10,24)}$ The fact that the aforementioned findings are inconsistent with those of the present study is probably due to the physiological nature of the tests employed, the $4 \mathrm{sET}$ being used in the present study in order to evaluate the parasympathetic nervous system.

In the present study, cardiac parasympathetic activity was found to have increased after surgery, a finding that might be due to the fact that the $4 \mathrm{sET}$ is a test that is reliable ${ }^{(16)}$ and has been validated ${ }^{(18)}$ for assessment of CVA by means of the CVI, a dimensionless index that reflects vagal withdrawal induced by rapid exercise. Assessment of HRV is used in most such studies; although HRV assessment is widely used in order to assess cardiac autonomic modulation, it has low reproducibility. ${ }^{(17,25-27)}$ Given that our study focused on assessing the cardiac parasympathetic nervous system, HRV assessment ${ }^{(28)}$ was not used.

In summary, parasympathetic nervous system activity was found to have increased at 1 month after sympathectomy for the treatment of primary hyperhidrosis. However, in the long term, mean resting HR values returned to baseline, suggesting a physiological adaptation 4 years after surgery.

\section{REFERENCES}

1. Stolman LP. Hyperhidrosis: medical and surgical treatment. Eplasty. 2008;8:e22.

2. Stolman LP. Treatment of hyperhidrosis. Dermatol Clin. 1998;16(4):863-9. https://doi.org/10.1016/S0733-8635(05)70062-0

3. Chung $\mathrm{IH}$, Oh CS, Koh KS, Kim HJ, Paik HC, Lee DY. Anatomic variations of the T2 nerve root (including the nerve of Kuntz) and their implications for sympathectomy. J Thorac Cardiovasc Surg. 2002;123(3):498-501. https://doi.org/10.1067/mtc.2002.119340

4. Montessi J, Almeida EP, Vieira JP, Abreu Mda M, Souza RL, Montessi OV. Video-assisted thoracic sympathectomy in the treatment of primary hyperhidrosis: a retrospective study of 521 cases comparing different levels of ablation. J Bras Pneumol. 2007;33(3):248-54 https://doi.org/10.1590/S1806-37132007000300004

5. KUX E. The endoscopic approach to the vegetative nervous system and its therapeutic possibilities; especially in duodenal ulcer, angina pectoris, hypertension and diabetes. Dis Chest. 1951;20(2):139-47. https://doi.org/10.1378/chest.20.2.139

6. McCorry LK. Physiology of the autonomic nervous system. Am J Pharm Educ. 2007;71(4):78. https://doi.org/10.5688/aj710478

7. Zimmermann M. Case studies in a physiology course on the autonomic nervous system: design, implementation, and evaluation. Adv Physiol Educ. 2010;34(2):59-64. https://doi.org/10.1152/ advan.00004.2010

8. Wiklund $U$, Koskinen LO, Niklasson U, Bjerle $P$, Elfversson J. Endoscopic transthoracic sympathicotomy affects the autonomic modulation of heart rate in patients with palmar hyperhidrosis. Acta Neurochir (Wien). 2000;142(6):691-6. https://doi.org/10.1007/ s007010070114

9. Wettervik MD, Claes G, Drott C, Emanuelsson H, Lomsky M, Rådberg $G$, et al. Endoscopic transthoracic sympathicotomy for severe angina. Lancet. 1995;345(8942):97-8. https://doi.org/10.1016/ S0140-6736(95)90065-9

10. Noppen M, Dendale P, Hagers Y, Herregodts P, Vincken W, D'Haens J. Changes in cardiocirculatory autonomic function after thoracoscopic upper dorsal sympathicolysis for essential hyperhidrosis. J Auton Nerv Syst. 1996;60(3):115-20. https://doi. org/10.1016/0165-1838(96)00034-3

11. Abraham P, Berthelot J, Victor J, Saumet JL, Picquet J, Enon B. Holter changes resulting from right-sided and bilateral infrastellate upper thoracic sympathectomy. Ann Thorac Surg. 2002;74(6):207681. https://doi.org/10.1016/S0003-4975(02)04080-8

12. Cole CR, Blackstone EH, Pashkow FJ, Snader CE, Lauer MS. Heartrate recovery immediately after exercise as a predictor of mortality. N Engl J Med. 1999:341(18):1351-7. https://doi.org/10.1056/ NEJM199910283411804
13. La Rovere MT, Bersano C, Gnemmi M, Specchia G, Schwartz PJ. Exercise-induced increase in baroreflex sensitivity predicts improved prognosis after myocardial infarction. Circulation 2002;106(8):945-9. https://doi.org/10.1161/01.CIR.0000027565.12764.E1

14. Thayer JF, Lane RD. The role of vagal function in the risk for cardiovascular disease and mortality. Biol Psychol. 2007;74(2):22442. https://doi.org/10.1016/j.biopsycho.2005.11.013

15. Sociedade Brasileira de Cardiologia; Sociedade Brasileira de Hipertensão; Sociedade Brasileira de Nefrologia. VI Brazilian Guidelines on Hypertension [Article in Portuguese]. Arq Bras Cardiol. 2010;95(1 Suppl):1-51. Erratum in Arq Bras Cardiol. 2010;95(4):553.

16. Araújo CGS, Ricardo DR, Almeida MB. Intra and interdays reliability of the 4-second exercise test. Rev Bras Med Esporte. 2003;9(5):293-8. https://doi.org/10.1590/S1517-86922003000500005

17. Paiva VC, Santana KR, Silva BM, Ramos PS, Lovisi JC, Araújo CG Ricardo DR. Comparison of assessment methods of cardiac vaga modulation. Arq Bras Cardiol. 2011;97(6):493-501. https://doi. org/10.1590/S0066-782X2011005000109

18. Araujo CG, Nobrega AC, Castro CL. Heart rate responses to deep breathing and 4-seconds of exercise before and after pharmacological blockade with atropine and propranolol. Clin Auton Res. 1992;2(1):3540. https://doi.org/10.1007/BF01824209

19. Prasad A, Ali M, Kaul S. Endoscopic thoracic sympathectomy for primary palmar hyperhidrosis. Surg Endosc. 2010;24(8):1952-7. https://doi.org/10.1007/s00464-010-0885-5

20. Zhang TY, Wang $L, X u J J$. The effects of thoracic sympathotomy on heart rate variability in patients with palmar hyperhidrosis. Yonsei Med J. 2012;53(6):1081-4. https://doi.org/10.3349/ymj.2012.53.6.1081

21. Tedoriya T, Sakagami S, Ueyama T, Thompson L, Hetzer R. Influences of bilateral endoscopic transthoracic sympathicotomy on cardiac autonomic nervous activity. Eur J Cardiothorac Surg 1999;15(2):194-8. https://doi.org/10.1016/S1010-7940(98)00309-1

22. Cruz J, Sousa J, Oliveira AG, Silva-Carvalho L. Effects of endoscopic thoracic sympathectomy for primary hyperhidrosis on cardiac autonomic nervous activity. J Thorac Cardiovasc Surg. 2009;137(3):664-9. https://doi.org/10.1016/j.jtcvs.2008.07.021

23. Schmidt JE, Wehrwein EA, Gronbach LA, Atkinson JL, Fealey RD, Charkoudian $\mathrm{N}$, et al. Autonomic function following endoscopic thoracic sympathotomy for hyperhidrosis. Clin Auton Res. 2011;21(1):11-7. https://doi.org/10.1007/s10286-010-0080-8

24. Senard JM, Simonetta-Moreau M, Tran MA. Blood pressure and heart rate variability in patients with essential hyperhidrosis. Clin Auton Res. 2003;13(4):281-5. https://doi.org/10.1007/s10286-0030104-8

25. Fiorelli A, Messina G, Chiodini P, Constanzo S, Viggiano A, Monda M, 
et al. Cardiac Autonomic Changes After Thoracic Sympathectomy: A Prospective, Randomized Study. Ann Thorac Surg. 2017;103(1):216224. https://doi.org/10.1016/j.athoracsur.2016.10.055

26. Kim SY, Euler DE. Baroreflex sensitivity assessed by complex demodulation of cardiovascular variability. Hypertension. 1997;29(5):1119-25. https://doi.org/10.1161/01.HYP.29.5.1119
27. Sandercock GR, Bromley PD, Brodie DA. The reliability of short-term measurements of heart rate variability. Int J Cardiol. 2005;103(2):23847. https://doi.org/10.1016/j.ijcard.2004.09.013

28. Vanderlei LC, Pastre CM, Hoshi RA, Carvalho TD, Godoy MF. Basic notions of heart rate variability and its clinical applicability. Rev Bras Cir Cardiovasc. 2009;24(2):205-17. https://doi.org/10.1590/S010276382009000200018 